\title{
Soft skills and dental education
}

Type: Article

Abstract:

Soft skills and hard skills are essential in the practice of dentistry. While hard skills deal with technical proficiency, soft skills relate to a personal values and interpersonal skills that determine a person's ability to fit in a particular situation. These skills contribute to the success of organisations that deal face-to-face with clients. Effective soft skills benefit the dental practice. However, the teaching of soft skills remains a challenge to dental schools. This paper discusses the different soft skills, how they are taught and assessed and the issues that need to be addressed in their teaching and assessment. The use of the module by the Faculty of Dentistry, University of Malaya for development of soft skills for institutions of higher learning introduced by the Ministry of Higher Education, Malaysia.

\begin{tabular}{|c|l|}
\hline Author & Gonzalez, M. A. G. ;Abu Kasim, N. H. ;Naimie, Z. \\
\hline Source & $\begin{array}{l}\text { European Journal of Dental Education } \\
\text { (A paid open access option is available for this journal) }\end{array}$ \\
\hline ISSN & $1396-5883$ \\
\hline DOI & $10.1111 /$ eje.12017 \\
\hline Volume (Issue) & $17(2)$ \\
\hline Page & $73-82$ \\
\hline Year & 2013 \\
\hline
\end{tabular}

Keyword:

soft skills; dental education; development; programme; teaching and learning; soft skills assessment; communication-skills; leadership development; students attitudes; hygiene students; assessment tools; health-care; curriculum; dentist; competence; performance; Dentistry, Oral Surgery \& Medicine; Education \& Educational Research

URL:

- http://apps.webofknowledge.com search via Accession No >> 000317608800003

- Full text available at : http://onlinelibrary.wiley.com/doi/10.1111/eje.12017/abstract 